\title{
The anatomy of mentoring relationships: it takes two to tango
}

\begin{abstract}
Ramani, S.
United States

"The delicate balance of mentoring someone is not creating them in your own image but giving them the opportunity to create themselves"- Steven Spielberg.

Mentoring is more than a unidirectional dyadic relationship between a senior mentor and junior mentee. Modern mentoring formats include peer mentoring, team mentoring, mentoring networks, one-time focussed interactions and reverse mentoring. Regardless of format, mentoring should be anchored by relationships, foster a climate psychological safety and enhance mutual growth.

Mentors as well as mentees have obligations and tasks in this relationship. Mentees should Be willing to reflect honestly about their strengths and weaknesses, open to stepping outside their comfort zone and proactive in formulating action plans for their own professional growth. Mentors, on the other hand, should not try to mould mentees in their own image. They should focus on establishing a safe climate where mentees can spread their wings, try new things and maximise their potential. Altruism, giving back to the profession and continued growth are valuable characteristics of mentors. This session will deconstruct a mentoring journey from the perspective of a mentor and mentee, review core features of successful mentoring relationships and reflect on challenges that can derail the relationship. We will conclude with a discussion of Daloz' model of mentoring which proposes that supporting mentees without challenging them would impede their professional growth.
\end{abstract}

6 